\title{
Review on Diagnostic Cytology: Techniques and Applications in Veterinary Medicine
}

Lema Ayele, Chala Mohammed and Lama Yimer*

School of Veterinary Medicine, Wollega University, Nekemte, Ethiopia

\begin{abstract}
Cytology is a science of cells that is used to differentiate between normal cells, neoplastic cells and inflamed cells. It has great acceptance than any other diagnostic methods due to its quickness, inexpensiveness and simplicity. It uses the techniques such as fine needle aspiration, impression, scraping, swabs, centesis and catheterization for sample collection. Also slide preparation uses a simple technique such as squash, blood smear; needle spread and line smear techniques. What makes cytology unique is that it can tell us the result of the diseases while the patient is with us. This science has also wide application on determining the external and internal diseases including neoplastic diseases. In case of neoplastic diseases it is important to differentiate between neoplastic nucleus, neoplastic cytoplasm and neoplastic structure of different cells with their normal cells. In addition to these, it also used in direct therapy, to form prognosis and to determinate next diagnostic procedures. Character of the lesion and tissue sampled play pivotal roles in the diagnostic value of cytology. Familiarity with preferred sampling methods and reported accuracy is critical for veterinary practitioners and sample of good quality is imperative. Different specimen sampling methods and specimen processing methods should be properly practiced.
\end{abstract}

\section{Keywords: Diagnostic; Cytology; Techniques; Tumor}

\section{Introduction}

The history of diagnostic cytology is like a winding road with many obstacles, but to the attentive traveler-the historian-brightly illuminated directional signs and familiar names are visible in the distance. Until the 19th century, microscopy was not respected in medicine. Such giants in pathology as the Italian Morgagni (16821771), the British Baillie (1761-1823), and the French Bichat (17711802), did not appreciate the utility of the microscope. Johannes Müller (1801-1858), a pathologist in Berlin, was the first, in 1838, to show cancer cells as they appeared in the microscope on scrapings from the cut surface of surgically excised tumors. He illustrated, among other things, cells of mammary carcinoma and osteosarcoma [1].

The 1920s were momentous years in diagnostic cytology. The first monograph of clinical cytology was published in Spain [2]. James Ewing (1866- 1943) introduced aspiration cytology in New York City [3] And Aurel Babes (1886-1961), of Rumania, and George Papanicolaou (1883-1962), of New York City, published papers on detection of uterine cervical cancers by examination of vaginal smears [4].

In the 1960s, cytology became accepted as a new specialty in pathology. During the next two decades, cytology branched out to all fields in medicine [5]. Cytology of even the most uncommon tumors became familiar to cytologists [6]. New and improved imaging techniques in radiology permitted rapid advances in aspiration cytology. Hitherto untouched, deeply situated organs such as the pancreas became easy targets for the aspirators [7]. The first monograph on aspiration cytology was published in 1974 by a Swedish hematologistcytologist [8] and a guide book on aspiration cytology was published in the United States in 1981 [9].

Diagnostic cytology is the science of interpretation of cells that are either exfoliated from epithelial surfaces or removed from various tissues $[10,11]$. It is a core veterinary pathology service involving specimens from domestic animals, laboratory animals, and exotic species. It can be carried out by different methods, which includes collection and examination of exfoliated cells such as vaginal swabs, sputum, urine, body fluids etc [12,13].
Unlike histopathology, cytology poorly differentiates tumors, cytological examination may not identify the tissue of origin (even differentiation between sarcomas and carcinomas can sometimes be extremely difficult). Cytology, therefore, should not be regarded as a substitute for histopathological examination of biopsy specimens. Histology is more likely to provide a definitive diagnosis and, since biopsies preserve tissue architecture, grading and classification of the tumor is usually possible [14].

The advantages of diagnostic cytology is that it is a non-invasive, simple procedure, helps in faster reporting, relatively inexpensive, has high population acceptance and facilitates cancer screening in the field. Many samples for cytology can be obtained without anesthesia or even sedation, with minimal risk in both healthy and critical patients [15]. With the increasing availability of ultrasonographic, many more internal organs and tissues can be evaluated than previously were accessible [16]. In many cases, a definitive cytological diagnosis can be made. However, even when a specific diagnosis cannot be rendered, the information provided by cytology (e.g., inflammatory versus neoplasia) is useful for choosing additional tests to make a definitive diagnosis (e.g., culture versus histopathology) [17].

So far, some work had been reported regarding diagnostic cytology in the World, but still the information on the role, application and techniques of diagnostic cytology is scattered and its applications and techniques particularly in veterinary medicine is not well documented These existing scattered information and different research outputs are

*Corresponding author: Lama Yimer, Wollega University, School of Veterinary Medicine, Nekemte, Ethiopia, Tel: +251917081237; E-mail: lemayimer@gmail.com

Received October 05, 2016; Accepted December 15, 2016; Published January 02, 2017

Citation: Ayele L, Mohammed C, Yimer L (2017) Review on Diagnostic Cytology: Techniques and Applications in Veterinary Medicine. J Vet Sci Technol 8: 408. doi: 10.4172/2157-7579.1000408

Copyright: ( 2017 Ayele L, et al. This is an open-access article distributed under the terms of the Creative Commons Attribution License, which permits unrestricted use, distribution, and reproduction in any medium, provided the original author and source are credited. 
to be wasted unless systematically reviewed and presented for public consumption.

Therefore; the objective of this review is: To compile, summarize and highlight the techniques and applications of diagnostic cytology in veterinary medicine.

\section{Basic Cell Types}

\section{Non-inflammatory cells}

What structure is being sampled? Even if the cells are not immediately recognizable, however, they can generally be classified into one of three major categories based on certain cytological features: discrete cells (or "round cells"), epithelial cells and mesenchymal cells. Categorizing cells into the major group to which they belong helps the evaluator to identify the specific cell type present. Even if precise identification cannot be made, relevant information may be gained, such as the presence of a cell type abnormal for the tissue sampled (e.g., epithelial cells in a lymph node aspirate) [18].

Discrete cells (round cells): Discrete cells are a group of cells that share certain cytological features owing to the fact that they are present individually in tissues and not adhered to other cells or connective tissue matrix. These are predominantly mobile cells of hematogenous origin. Aspirates of normal lymphoid tissue, such as spleen and lymph nodes, yield cell populations that have a discrete cell pattern. Other than normal lymphoid tissue, a discrete cell pattern usually indicates the presence of one of a group of tumors termed discrete cell tumors (or round cell tumors). Recognition of discrete cell tumors is important, because these are some of the more common neoplasms encountered in small animal practice. Also, cells of most discrete cell tumors have cytological characteristics that are sufficiently distinct so as to allow for a specific diagnosis. The discrete cell tumors are mast cell tumor, lymphosarcoma (lymphoma), histiocytoma, plasmacytoma, and transmissible venereal tumor (TVT). In addition, melanomas are the great imitator, yielding cell populations that may appear discrete, epithelial, or mesenchymal [10].

Epithelial cells: Normal epithelial cells are commonly encountered in many cytological preparations. Surface epithelium is present in most surface scrapings and swabs (e.g., squamous cells from skin scrapings and nasal or vaginal swabs), washings (e.g., columnar cells from transtracheal washes), and as the result of normal exfoliation (transitional cells from urine sediments). Epithelial cells may also originate from a hyperplasic proliferation or neoplasm [19].

Mesenchymal cells: Mesenchymal cells are cells of connective tissue origin. Because blood is a connective tissue, hematopoietic cells (including many of the cells described as "discrete cells") are included as mesenchymal tissue. Because these hematopoietic cells have a cytological appearance so distinct from the other connective tissues, they are typically classified separately. Most often, the discussion of "mesenchymal cells" in cytology texts implies "stromal" connective tissue cells [10]

\section{Inflammatory cells}

The basic types of inflammatory cells are: neutrophils, macrophages, lymphocytes and eosinophils are the most common one. Most clinicians initially feel more comfortable recognizing inflammatory cells because they are more familiar with the morphology of these cells, having viewed them many times in peripheral blood smears. Many clinicians choose to screen their cytology specimens, interpreting inflammatory lesions in-house but submitting those composed of tissue cells for outside evaluation [10].

\section{Types of Cytological Techniques}

\section{Solid tissue sample collection techniques}

The ideal methods of sampling for cytology may vary with the type and location of the lesion, differential diagnostic list, and patient temperament. Sample types for cytological evaluation include swabs, impression smears, scrapings, tape preparations, and needle aspirates. These different types of samples are acquired by using different method discussed below [20].

Fine needle aspiration techniques: The best and most commonly used method for sampling proliferative lesions and masses. We recommend using a 22-25 gauge needle and a 2-5 ml syringe and as a general rule, the softer the tissue, the smaller the needle and syringe required obtaining an adequate sample for organs such as the liver or spleen, longer needles are usually required. It is a useful technique for the investigation of soft tissue masses (cutaneous lesions, lymph nodes, intra-thoracic or intra-abdominal masses) and effusions from body cavities. The technique can be easily performed in a practice setting. Fine-needle aspirates can be taken with an 'aspiration technique' or a 'non-aspiration technique' [21].

Aspiration technique: Once the mass is stabilized between the operator's fingers, the fine gauge needle is inserted into the mass. When the needle is seated comfortably in the mass, negative pressure is applied to the plunger/syringe (Figure 1). Try and avoid redirecting the needle or moving it back and forth within the mass whilst vacuum (negative pressure) is applied as this generally results in increased blood contamination of samples. This procedure should be repeated at least 3-4 times at different angles within the lesion to obtain a representative cell population from the lesion in question. Smaller syringes attached to the needle offer the operator better control during the aspiration process, particularly when aspirating smaller lesions. A minimal amount of material within the hub of the needle is adequate and generally this is sufficient for cytological interpretation. Attempted further aspiration often leads to unwanted blood contamination. If blood is encountered during aspiration attempts, then the exercise should be ceased and repeated a little further away from the initial puncture site. Negative pressure should be released before the needle is removed from the mass and skin. Once the needle is removed from the syringe, air is drawn into the syringe and the needle is firmly reattached to the syringe [8].

Non aspiration technique (also known as woodpecker method): The non-aspiration technique is preferred for sampling of all masses or organs which are highly vascular (e.g. spleen, liver) in order to minimize blood contamination. Overall, the sampling procedure should take no longer than 5-10 s and several smears should be prepared. The non aspiration technique using a 'needle alone technique' is useful for obtaining samples from small lesions such as pustules (Figure 2A). The non-aspiration technique with the syringe attached to the needle is used here to sample the spleen of a dog with ascites and icterus under ultrasonographic control (Figure 2B). Note the syringe is prefilled with air and is held between the thumb and forefinger [21].

Impression techniques: Impression smears may be collected from cutaneous ulcers or exudative lesions, from masses that have been surgically removed, and from tissues at necropsy (Figure 3). Ulcers should be imprinted, cleaned, and re-imprinted. To collect impression smears from tissues collected at surgery or necropsy, the tissue to be imprinted should first be cut in half to have a fresh surface. The fresh surface is then blotted (e.g., paper towel, surgical gaze) to remove as 

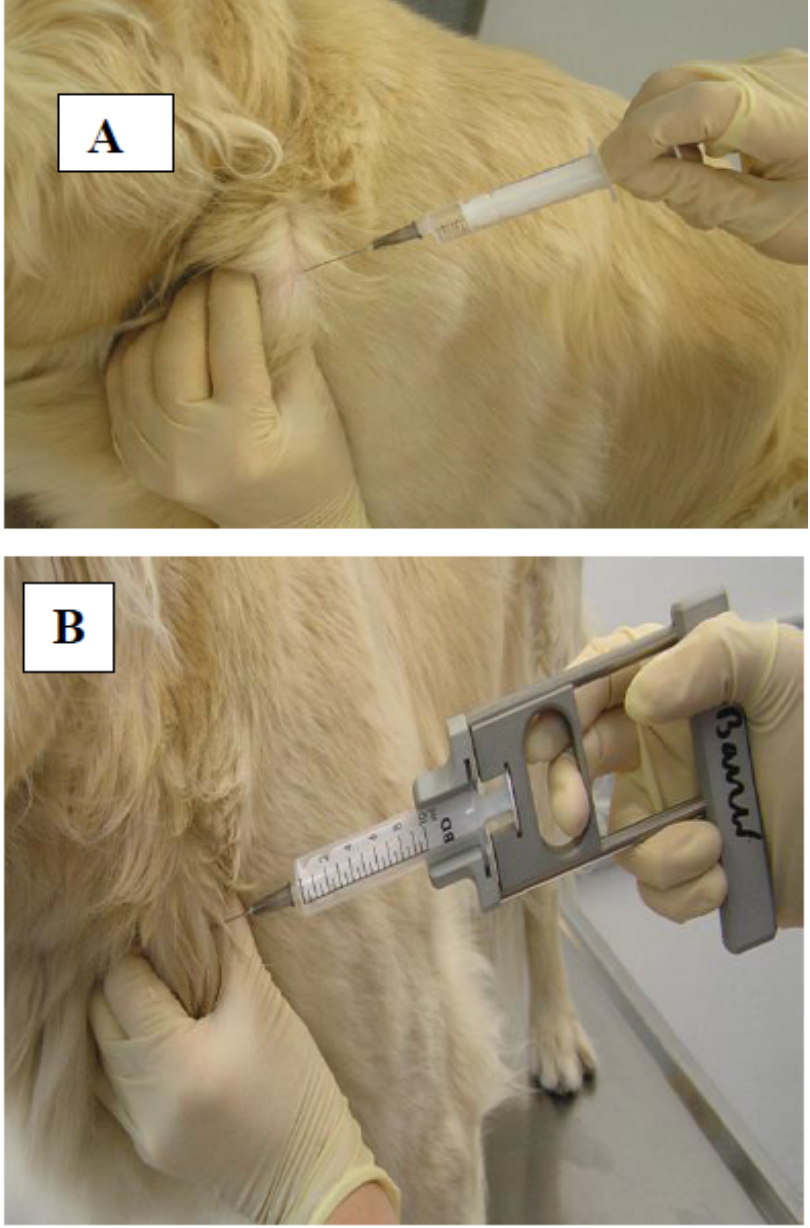

Figure 1: (A) Fine-needle aspiration using a needle and syringe. (B) Fineneedle aspiration using an aspiration gun [21]. much of the blood and tissue fluid as possible. The fresh surface is then touched to a clean glass slide. No further smearing is needed. One must not slide the tissue around on the glass slide, but simply press down and lift directly up. The material is allowed to air-dry [22]. Do not rub the tissue on the slide as this will result in distorted cellular morphology by causing cell rupture and nuclear stranding. The most common problems encountered with touch imprints are inadequate blotting of the specimen and 'non-exfoliative lesions [23]. The disadvantages of impression smears are that they only collect cells from the surface of the lesion and therefore may not be representative of underlying pathology, fewer cells are collected and bacterial contamination is more likely [21].

Swabs: Swabs are generally used only when other collection methods are not practical (e.g., ear canal, vaginal cytology, fistulous tracts). If the area to be swab is dry, it is best to wet the swab with sterile saline. In addition, if culture is to be done, a sterile cotton swab should be used. After swabbing the area, the cotton swab is simply rolled on a glass slide and the smear allowed to air dry (Figure 4). They are less useful for described for impression smears [10].

Scrapings: Scrapings are used for superficial skin lesions and may be more representative of deeper abnormality than impression smears of similar lesions. Superficial crusts and exudates should be gently removed or blotted away from the lesion first. Samples are then collected by scraping a scalpel blade across the surface of the lesion, followed by transfer of the material from the blade to a clean glass slide, smeared, and allowed to air-dry (Figure 5). This method has similar uses to imprinting, but may also be used where imprinting is likely to yield too few cells for complete assessment (e.g., conjunctiva, mesenchymal neoplasia) [16].

Tape preparation: A method for evaluation of skin disease is particularly for detecting malessezia dermatitis and skin mites (Figure 6). A piece of clear, pressure-sensitive tape is placed on the skin lesion. The tape strip is removed and fixed on a microscopic slide containing a drop of blue (counter) stain [24].

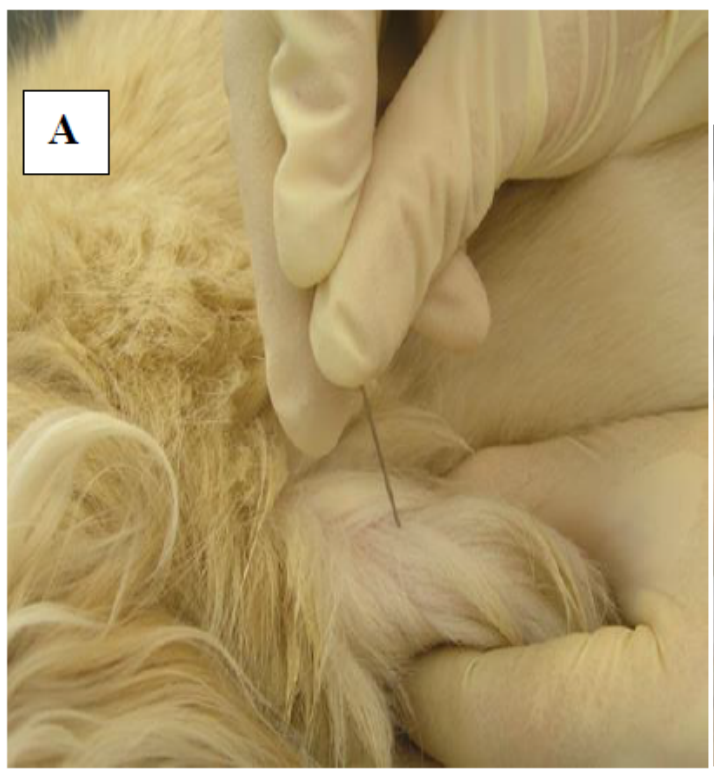

Figure 2: (A) The non aspiration technique using a 'needle alone technique'.

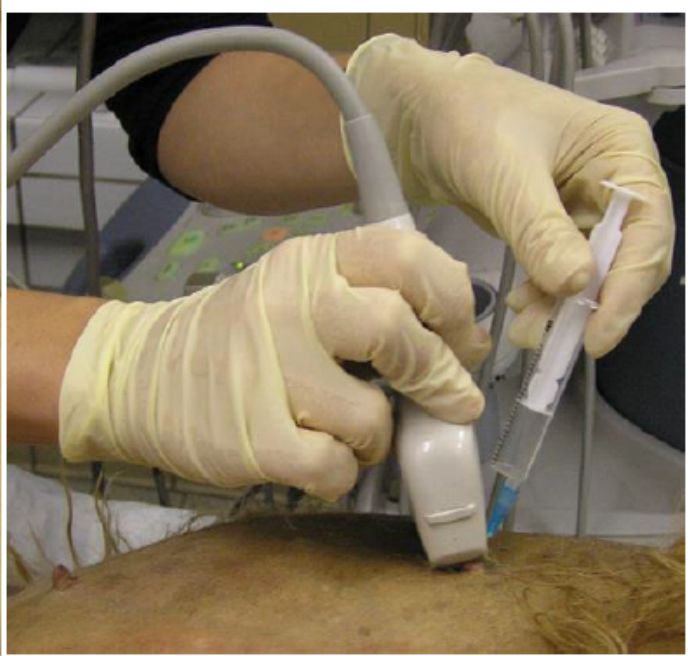

(B) The non aspiration technique with the syringe attached to the needle [21] 

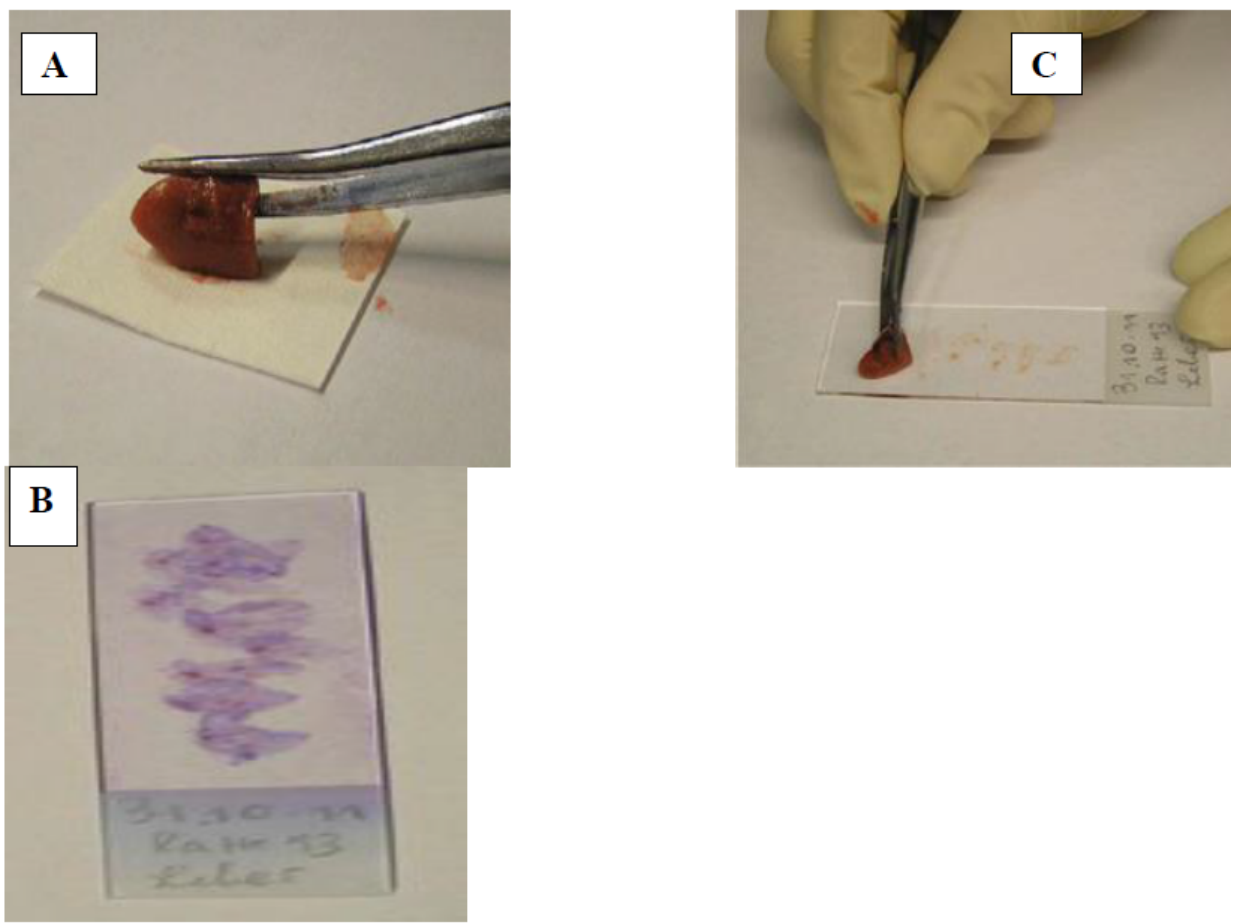

Figure 3: Impression smear of a liver biopsy. (A) Blotting gently on a filter paper. (B and C) The imprint smear is prepared by touching the slide with the surface of the biopsy in several areas [21].
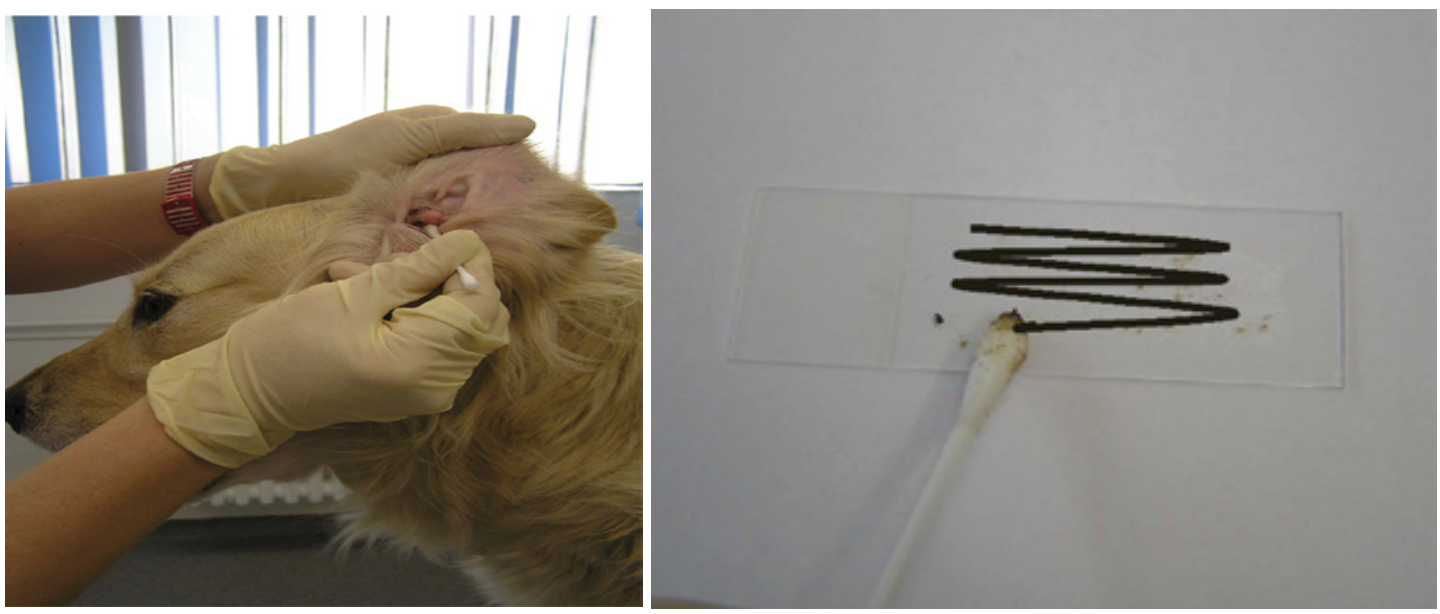

Figure 4: Collection of an ear swab for cytological investigation. (A) The cerumen or discharge is collected with a cotton bud. (B) Note the meandrical movement of the cotton bud [21].

\section{Solid tissue slide preparation techniques}

Slide-over-slide technique ("squash") preparation: For the squash preparation, material collected by one of many techniques (e.g., aspiration or non-aspiration fine-needle biopsy, scrapings) is placed in the middle of a clean glass slide (smear slide). A second glass slide (spreader slide) is placed over the sample perpendicular to the smear slide (Figure 7). The sample will begin to spread out due to the weight of the spreader slide. Once the sample has begun to spread, the spreader slide is gently drawn across the sample slide, smearing the sample One must be careful not to put any downward pressure on the spreader slide. Excessive pressure will cause cells to rupture. The slide-over-slide technique works well for spreading samples from nonfragile tissues (e.g., carcinomas). However, squash preparation tends to rupture excessive numbers of cells from more fragile tissues (e.g., lymph nodes). Once spread, the material is allowed to air-dry; No fixative is needed [25].

\section{Fluid cytology (exfoliative cytology) sample collection techniques}

Catheterization: Catheterization means collecting samples by performing various types of washes (e.g., bronchoalveolar lavage, transtracheal wash (Figure 8). Volume permitting, fluid aliquots 
Citation: Ayele L, Mohammed C, Yimer L (2017) Review on Diagnostic Cytology: Techniques and Applications in Veterinary Medicine. J Vet Sci Technol 8: 408. doi: 10.4172/2157-7579.1000408

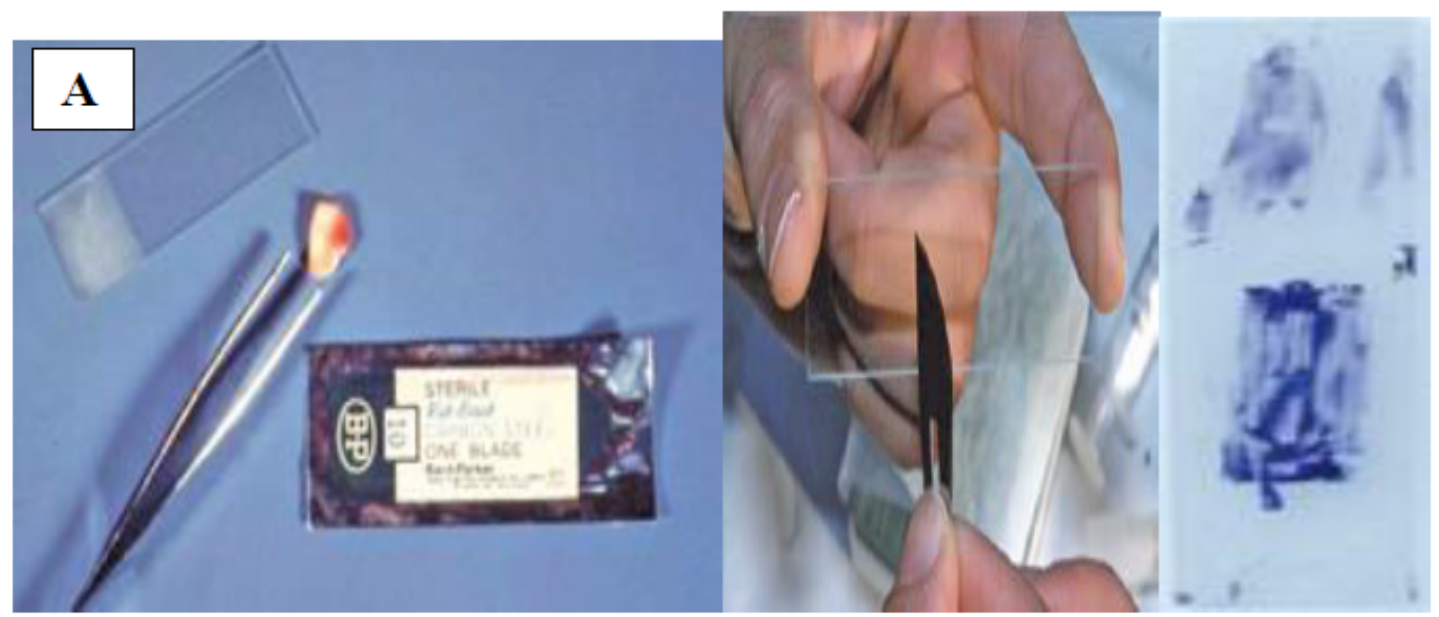

Figure 5: Tissue scrapping. (A and B) Scrape across the lesion or tissue biopsy until a small amount of material is collected. (C) This material is then gently spread across a slide [23].
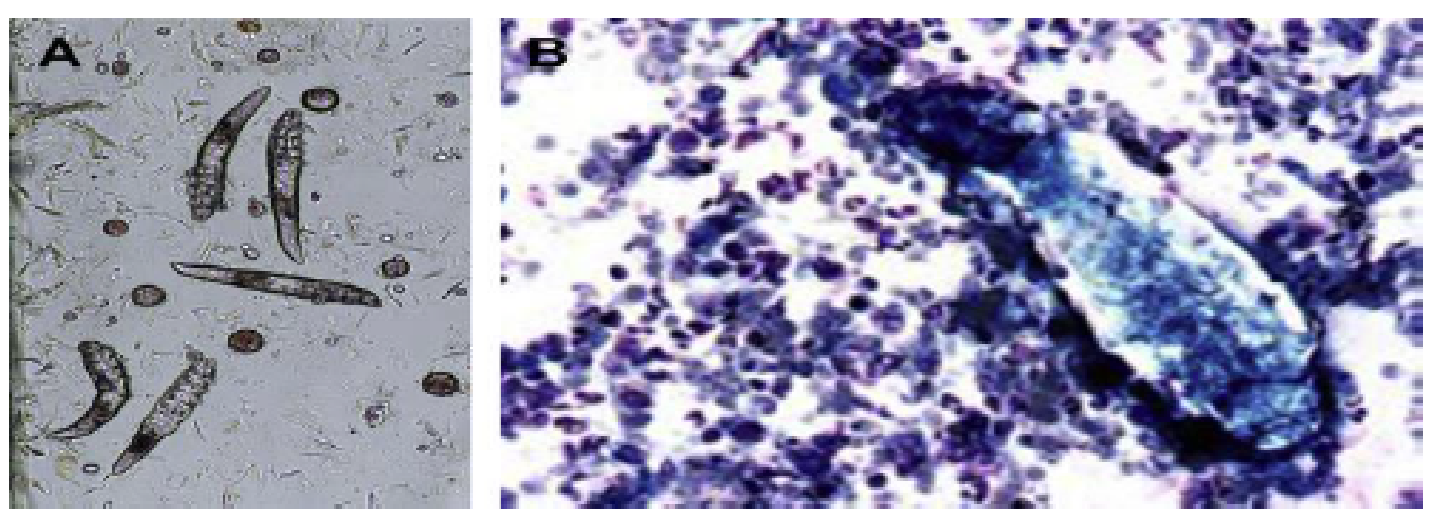

Figure 6: Tape preparation. Demodex (A) Unstained skin preparation. (B) Mite among inflammatory cells in a Wright-Giemsa-stained cytology preparation [24].

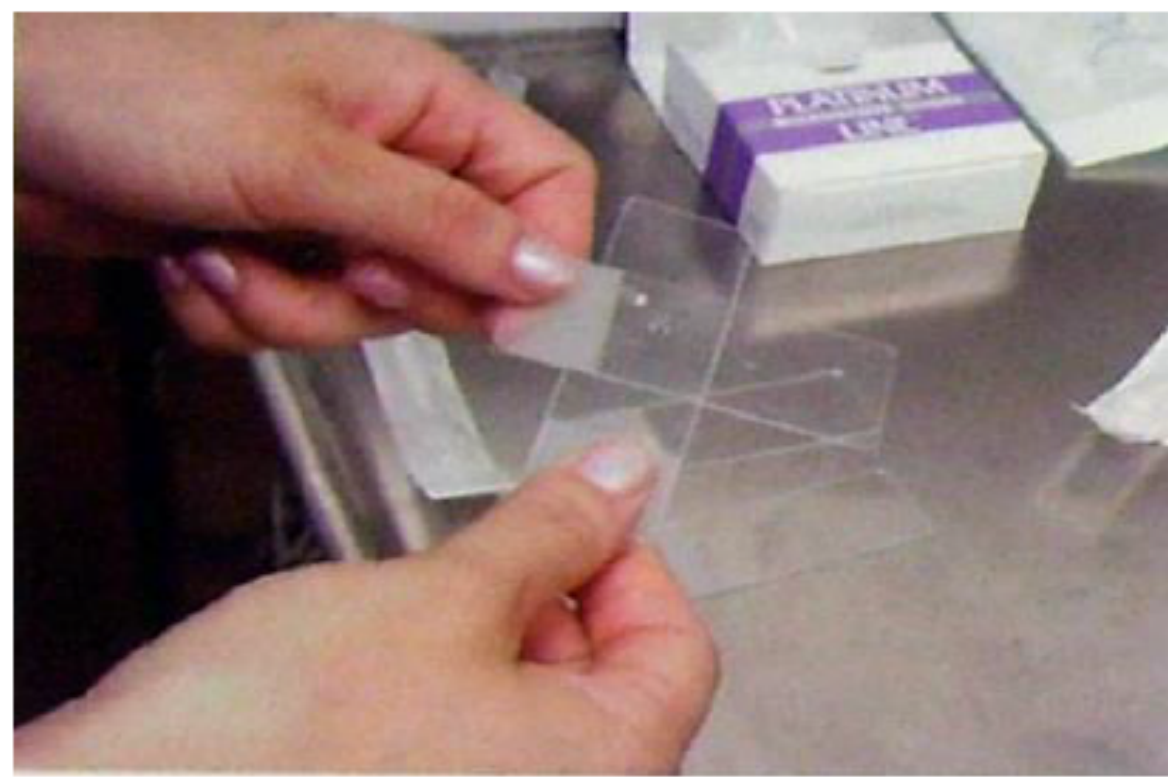

Figure 7: Squash preparation [26] 
should be collected into EDTA-containing tubes and sterile/plain tubes. Smears should also be made at the time of sampling. EDTA prevents coagulation and therefore allows for accurate cell counts to be performed when required [26,27].

Centesis: Centesis means aspiration of fluid or air from the body cavity by tabbing with aspirator, trocar, or needle (Figure 9). Sample is hold in the same manner as catheterization [28].

\section{Fluid cytology (exfoliative cytology) slide preparation techniques}

Blood smear technique: The collected material is placed near one end of a glass slide (smear slide) (Figure 10A). The spreader slide is tilted to an angle of approximately 45 degrees, pulled backwards into the material (Figure 10B) and once the material has dispersed along the width of the spreader slide, the spreader slide is smoothly, steadily and rapidly slid forward (Figure 10C). The smear ends with a feathered edge of material (Figure 10D). As a general rule, the more material placed on the specimen slide, the slower the spreader slide is slid forward and the more acute the angle between the spreader and specimen slide, the longer the smear will be. The blood smear technique has much less shearing force than squash preparation and causes less cell rupturing. However, blood smearing does not spread cells as well as using slide over slide [13].

Star fish preparation (needle spread) technique: A material collected by fine needle biopsy is placed in the centre of a glass slide (Figure 11A) and the needle is used to drag/tease the material outwards in multiple directions to produce a star/starfish shaped smear with multiple projections (Figure 11B). Many areas of the smear will be too thick for evaluation, however, there is usually multiple cell monolayer regions present on the smear that should be acceptable for cytological assessment. This technique minimizes the amount of trauma to fragile cells and is useful if only a small volume of material is aspirated. It is used in both solid and liquid cytology slide preparation techniques [1].

Line smears technique/role preparation: The line smear technique is useful for concentrating cells in a fluid sample when the sample cannot be centrifuged to make smears from the sediment. A drop of fluid is placed near one end of a glass slide (smear slide). A second slide (spreader slide) is placed on the smear slide at a 45-degree angle and backed up until it contacts the drop of fluid. Moderate downward pressure is applied, causing the nucleated cells to follow just behind the spreader slide (e.g., pulling out to end of smear). The spreader slide is then pushed forward as of making a blood smear, except a feathered edge is not created. After being advanced about two-thirds to threefourths the distance required to make a smear with a feathered edge, the spreader slide is stopped and then lifted directly up. This creates a line at the end of the smear that has a much higher concentration of nucleated cells [13].

\section{Cytological stains}

Romanowsky-type stains (Wright's, Giemsa and Diff-Quick stain): Romanowsky stains are inexpensive, easy to use and they are readily available to veterinary practitioners. They provide good nuclear detail; excellent cytoplasm detail and infectious organisms are readily visualized. In clinical practice, the most cost effective, quickest and easiest stain to use is the Diff-Quick stain [20].

Papanicolaou stains: Papanicolaou stains provide excellent nuclear detail and adequate cytoplasmic detail, however, they are time consuming and impractical for in-clinic usage. Supravital stains provide

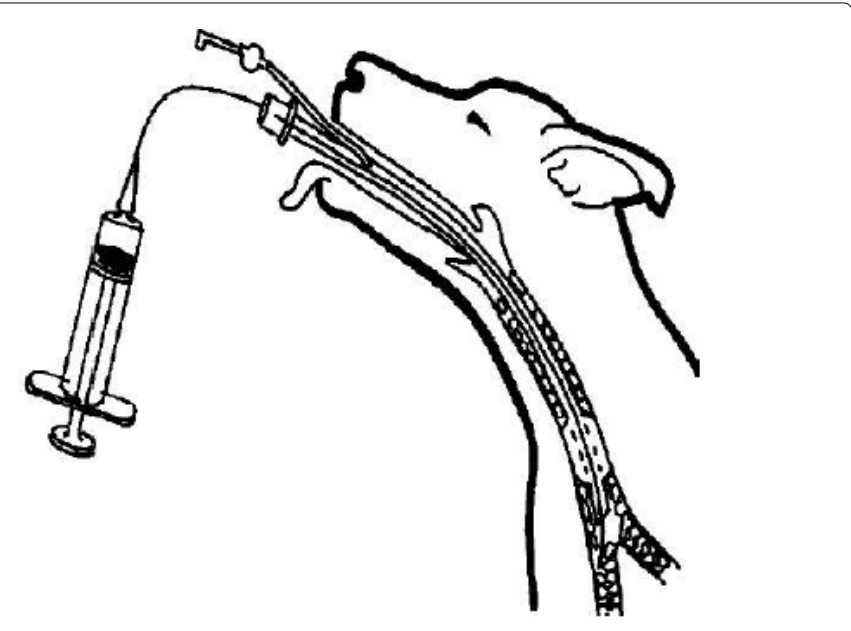

Figure 8: Transtracheal wash [27].

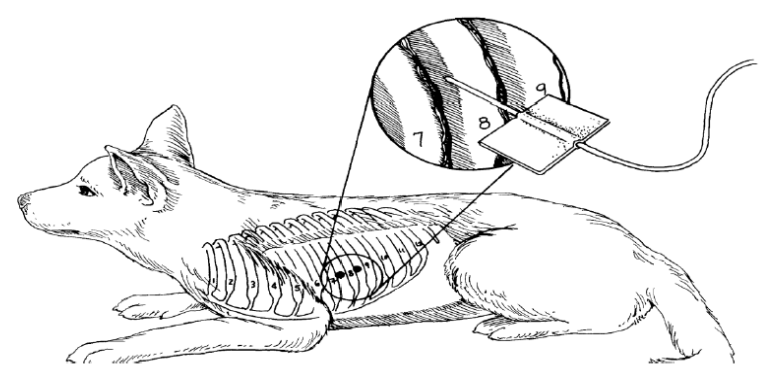

Figure 9: Thoracocentesis [28].
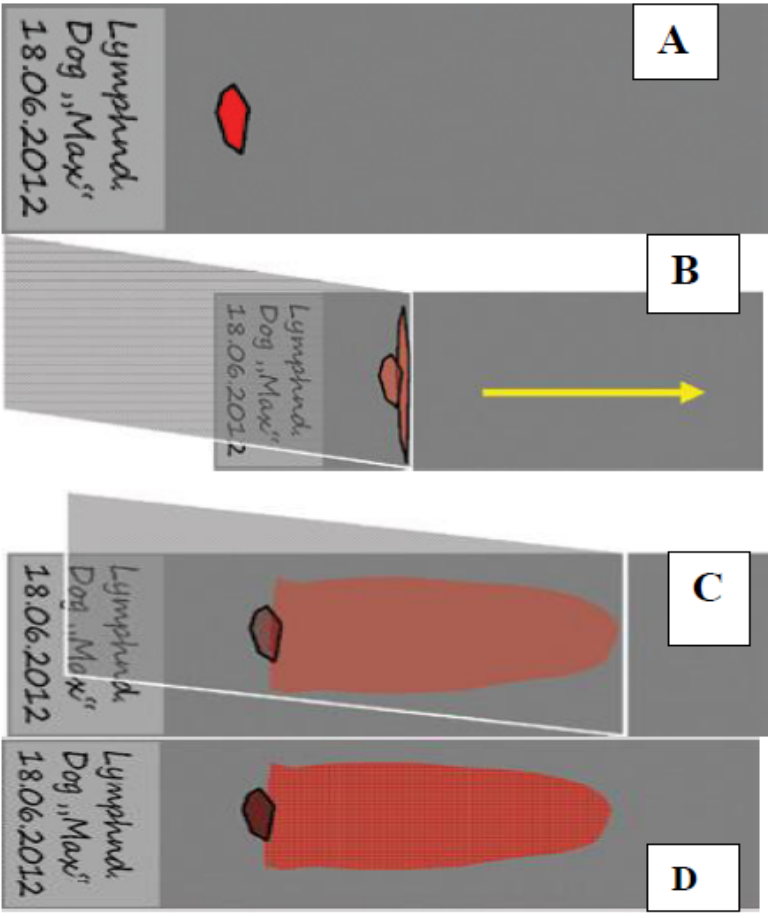

Figure 10: Preparation of the smear using a blood smear technique [21]. 


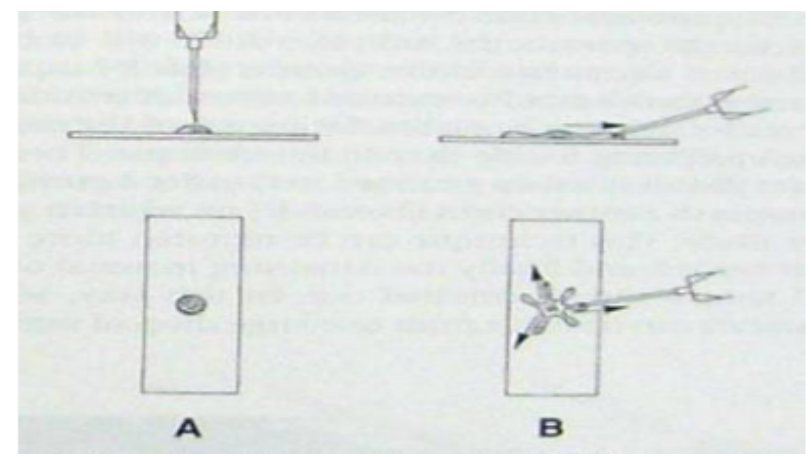

Figure 11: Needle spread or "starfish" preparation [26].

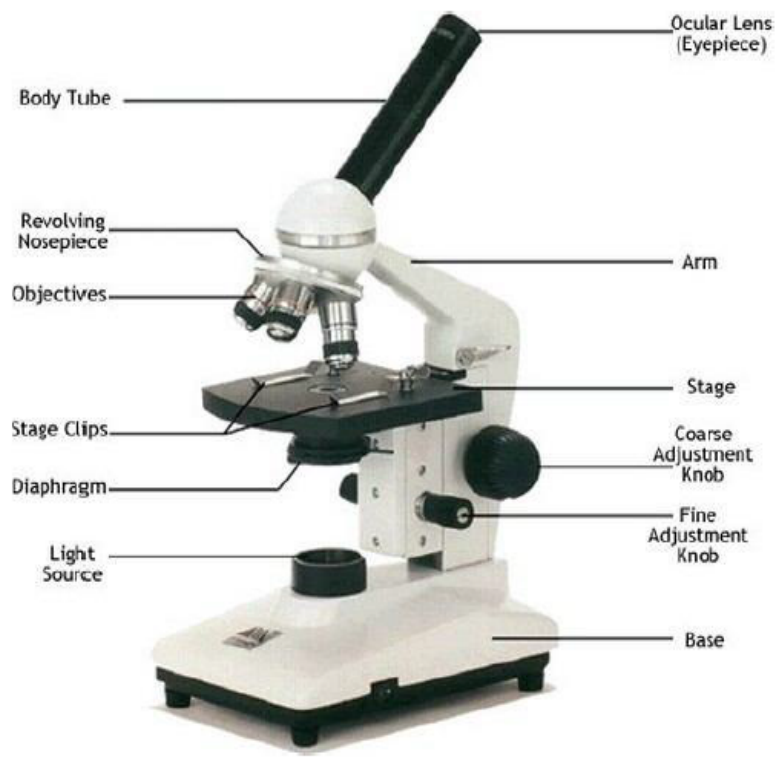

Figure 12: A Modern Day Light Microscope [30].

excellent nuclear detail but poor cytoplasmic detail and are typically reserved for evaluation of reticulocyte identification (peripheral blood smear) or for evaluating the presence of poorly granulated mast cells [29].

\section{Microscopic evaluation}

The light microscope is the basic tool that is used to observe objects too small to be seen with the unaided eye. Objects or specimens are magnified up to about one hundred times and as such could be observed using light microscope. The ability to distinguish between two objects as separate entities is referred to as resolution. The first objective or lens normally used in microscopic work is X10, Medium objective X20, high power objective X40 and oil immersion X100 (Figure 12) [30].

\section{Applications of Cytology in the Diagnosis of Animal Diseases}

Cytology is an inexpensive yet powerful diagnostic tool that allows for rapid diagnosis of many common diseases. There is great potential for application of cytological diagnosis to variety of medical conditions. Some of most important application being applied in veterinary medicine has discussed below [31].

\section{Cytological diagnosis of tumor}

A uniform population of cells suggests the mass is benign, whereas variation in cells suggests malignancy. An important exception is lymphoma (lymphosarcoma), which consists of a fairly uniform population of lymphoblast, whereas lymphoid hyperplasia typically has marked variation due to the mixed population of small lymphocytes, lymphoblast, and plasma cells. Nuclear criteria of malignancy are considered diagnostic, whereas cytoplasmic criteria of malignancy are only supportive of malignant neoplasia. It is important to find more than three of the following nuclear criteria of malignancy in a few cells to many cells to call a mass malignant neoplasia. The cytological criteria of malignancy are basically based on nucleus and cytoplasm of cells under neoplastic transformation [32].

Nuclear criteria of malignancy include variation in nuclear size (Anisokaryosis) with increased nuclear size $(>10 \mu \mathrm{m})$ (macrokaryosis) and increased nuclear/cytoplasmic ratio: large nucleus and less cytoplasm (but it is normal in some cell types, such as in small lymphocyte). Macro-nucleoli: are nucleoli that are greater than $5 \mu \mathrm{m}$ in diameter. Abnormally prominent nucleoli with variable shapes: nucleoli are angular instead of round or oval. Abnormal mitosis with improper alignment of chromosomes, coarse chromatin pattern (ropy or cordlike chromatin) and nuclear molding that is nucleus deformed (molded) around other nuclei within the same cell or other cells which indicates loss of contact inhibition are nuclear characteristics of malignancy [33]. Cytoplasmic Criteria of Malignancy includes cytoplasmic basophilic that is increased ribonucleic acid (RNA) synthesis/content [32].

Mast cell tumors: Must cell tumors are among the most common cutaneous neoplasms of dogs and cats; however, they may occur at any anatomic location both as primary and secondary neoplastic diseases. They are most commonly seen in middle aged dogs and cats, but any age animal is susceptible [34].

Interpretation: Mast cells are recognized by their distinctive small red-purple intracytoplasmic granules. Most mast cell tumors yield cells that contain a sufficient number of granules to be easily recognized as mast cells. These granules are the most distinctive feature of mast cell tumors (see arrows in figure below). Rupturing of some cells can lead to the presence of numerous free granules in the background (see arrowheads in figure below). The cells have a round to oval nucleus that may be obscured by the granules. Variable numbers of eosinophils are present. It is important to remember that some stains (e.g., Diff-Quik) occasionally will not stain the mast cell granules [33].

Histiocytoma: Histiocytoma are benign tumors of macrophage origin that are common in young dogs. They are exfoliate small, benign-appearing, round, discretely oriented cells [35].

Interpretation: Histiocytoma have a moderate amount of homogeneous clear to gray to blue-gray cytoplasm that often stains lighter than the surrounding tissue fluid background. These cells have a round to oval nucleus, finely stippled chromatin, and indistinct nucleoli. Lymphoid cells (none - many) may also be present (Figures 13 and 14). Moderate to high numbers of small lymphocytes suggest an immune response and that the Histiocytoma is about to regress spontaneously [36].

Transmissible venereal tumors (TVT): Canine Transmissible Venereal Tumor (CTVT) also known as infectious sarcoma, venereal granuloma, transmissible lymphosarcoma or Sticker tumor, is a benign reticuloendothelial (histiocytic) tumor of the dog that mainly affects 
the external genitalia [37]. CTVT has cauliflower-like shape, and it could be pendular, nodous, papilar, or multilobular (Figure 15A) [38]. They are sexually transmitted tumors of dogs. They are usually found on mucous membranes such as the penis, vagina, and nose but can be found in many other areas to which they have metastasized. They are often malignant in behavior, but respond well to chemotherapy and radiation therapy [33].

Interpretation: CTVT cells are large round cells with round nucleus, coarse chromatin, one to two prominent nucleoli, abundant and lightly basophilic cytoplasm and multiple punctate vacuoles (Figure 15B) [39].

Mesenchymal cell tumor: Benign mesenchymal tumors tend to exfoliate few cells, and samples of diagnostic quality may be difficult to obtain. In contrast, malignant mesenchymal tumors may yield highly cellular aspirates. The cells are usually individually oriented, although large clusters may be present, particularly if held together by an extracellular matrix [40].

Interpretation: In contrast to the other cell types (discrete and epithelial), the cytoplasmic borders of mesenchymal cells are often indistinct (i.e. the cytoplasm seems to fade gradually into the background) and making it nearly impossible to distinguish the limits of the cell membrane (Figure 16). Ruptured cells may also have indistinct cytoplasmic borders, but the nuclear membrane is usually disrupted in these traumatized cells, whereas the nuclear outline of intact mesenchymal cells is well defined [41].

\section{Exfoliative cytology (body cavity effusion cytology)}

Cytological characteristics of neoplastic effusion: Tumor cells in effusions are generally recognized by finding high numbers of immature (blastic) cells (e.g., lymphoblast) in the effusion or by finding epithelial cells (or rarely spindle cells) with sufficient criteria of malignancy to make a diagnosis of neoplasia. It is important not to confuse reactive mesothelial cells with carcinoma cells, especially in pericardial effusions. Many Neoplastic effusions do not exfoliate Neoplastic cells into the fluid, and in these effusions, neoplasia cannot be diagnosed cytologically [42].

Cytological characteristics of feline infectious peritonitis: Thoracic and peritoneal fluid collected from a cat with effusive infectious peritonitis is usually relatively low in cells $[1500 / \mu \mathrm{l}$ to $5000 / \mu \mathrm{l}]$ but in occasion may be high $[25000 / \mu \mathrm{l}]$ and high in protein content [5 to 10 $\mathrm{gm} / \mathrm{dl}$ ] may be recognized by the presence of a stained background on which other cells rest. The fluid usually clots but bacteria are rarely seen. In the acute form of FIP, well-preserved intact neutrophils predominate with a few mono nuclear cells. In more chronic cases, macrophages, lymphocytes and mesothelial cells are more numerous than neutrophils [43].

Cytological characteristics of nocardiosis: Nocardiosis may produce a pleural effusion in cats and dogs that is characteristically atypical purulent exudates. Fibrinous material with flakes or small granules is frequently collected. Microscopic examination reveals clumps of branching often beaded filaments resembling rods or cocci may also be present [43].

\section{Application of cytology in liver disease diagnosis}

Physical examination, clinical laboratory testing, and medical imaging are effective in establishing the presence of liver disease; however, they infrequently establish a definitive diagnosis. Morphologic evaluation of liver tissue is generally accepted as a valuable diagnostic

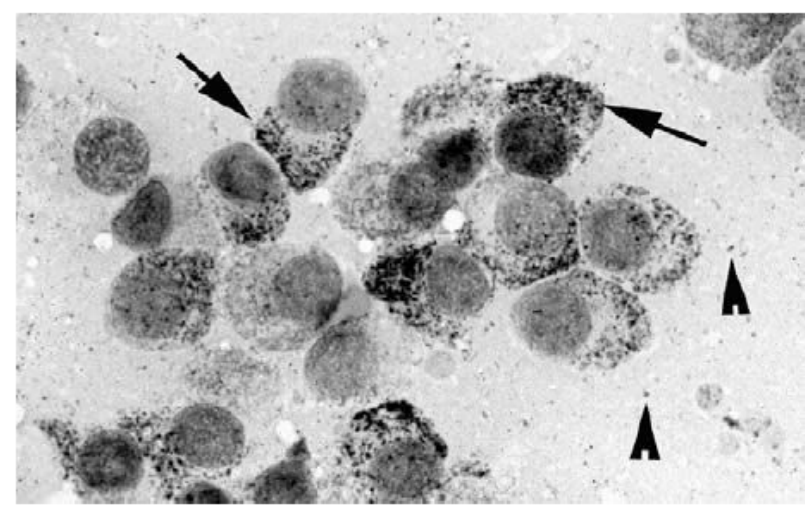

Figure 13: Smears made from an aspirate of a mast cell tumour [35].

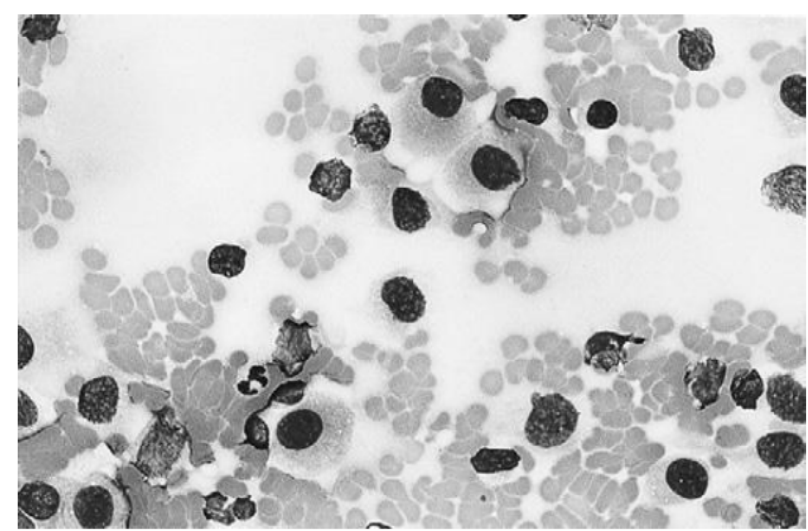

Figure 14: Smears made from a Histiocytoma [33].

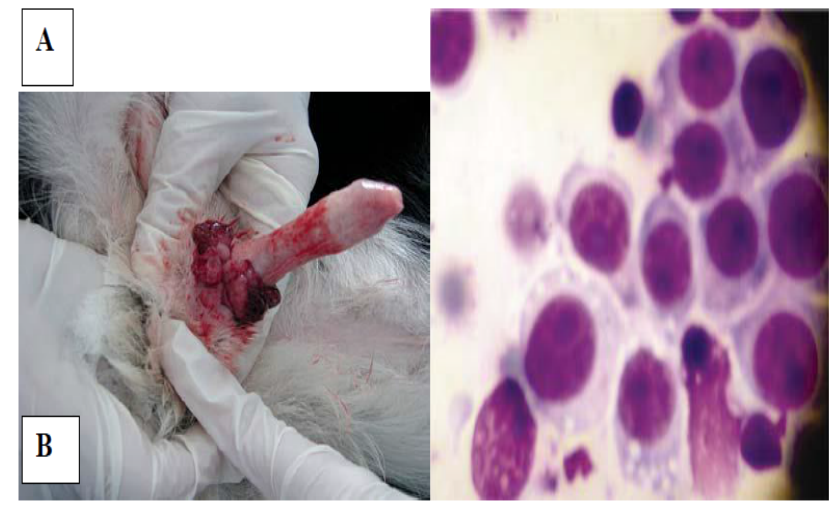

Figure 15: Radix penis Dog with Cluster of CTVT cells [40].

tool in establishing a diagnosis in liver disease [41].

Cytology of hepatocellular carcinomas: They may be composed of hepatocytes that appear relatively normal and cannot be definitively recognized cytologically as malignant, or they may be composed of atypical hepatocytes that are easily recognized as malignant. Therefore, hepatocellular carcinomas that have extremely anaplastic hepatocytes can be diagnosed cytologically, but many cannot and require histopathology [41]. 


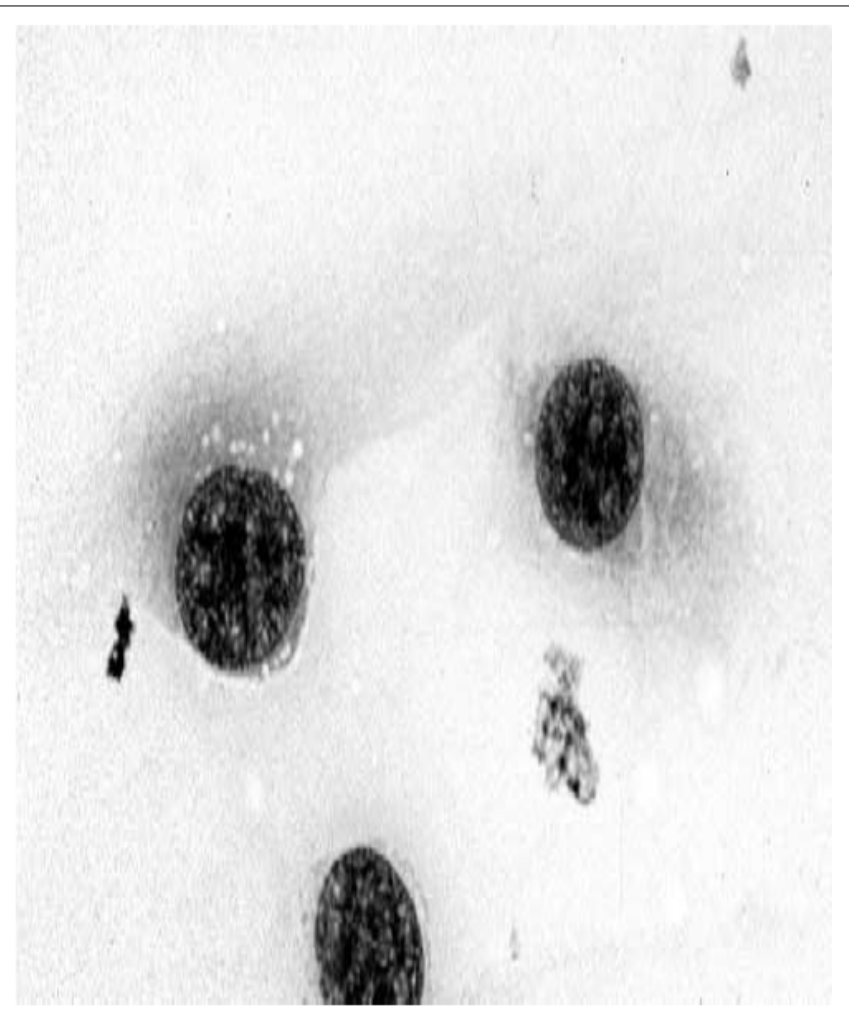

Figure 16: Cells from a tumour of mesenchymal origin [36].

Cytology of bile duct tumors: Because of the diffuse nature of many bile duct tumors, the potential for cytological diagnosis is good. Both bile duct adenomas and carcinomas tend to exfoliate relatively normal-appearing bile duct epithelial cells. These cells tend to be in tightly adhered clusters or sheets. Occasionally, acinar formation is observed. Some adenocarcinomas will have malignant criteria that allow for a diagnosis, whereas others will require histopathology for a definitive diagnosis [44].

\section{Conclusion}

Diagnostic cytology is the science of interpretation of cells that are either exfoliated from epithelial surfaces or removed from various tissues. It can be carried out by different methods and it has many applications in diagnosing and confirming different diseases. Cytology is an inexpensive yet powerful diagnostic tool that allows for rapid diagnosis of many common diseases. Cytological examinations identify disease process; neoplasia versus inflammation, specific versus nonspecific inflammation. In addition to these, it also used in direct therapy, to form prognosis and to determinate next diagnostic procedures. Character of the lesion and tissue sampled play pivotal roles in the diagnostic value of cytology. Familiarity with preferred sampling methods and reported accuracy is critical for veterinary practitioners and sample of good quality is imperative.

Based on the above conclusion, the following recommendations are forwarded:

Detailed, active communication between practicing veterinarians and clinical pathologists should be strengthened to increase the diagnostic accuracy of cytology.

Different specimen sampling methods and specimen processing methods should be properly practiced.

Role of cytology and its diagnostic accuracy should be systematically reviewed and analyzed in detail along with research gaps for future outlook

\section{References}

1. Steven I, Hajdu H, Ehya H (2008) Foundation of Diagnostic Cytology. Annals of Clinical \& Laboratory Science. 38: 296-299.

2. Dargallo R (1920) Anlisis Clinico Delos Esputlos. Calpe, Madrid.

3. Ewing J (1922) Neoplastic Diseases. Saunders, Philadelphia, USA.

4. Babes A (1928) Diagnostic du cancer du col uterin par les frottis. Presse Med 36: $451-454$

5. Johnson WW, Frable WJ (1979) Diagnostic Respiratory Cytopathology Masson, New York, USA

6. Ehya H, Hajdu SI, Melamed MR (1980) Cytopathology of nonlymphoreticula neoplasms metastatic to the central nervous system. Acta Cytol 25: 599-610.

7. Haaga J, Reich NE, Mosby CV, Hattery RR (1978) Computed Tomography of Abdominal Abnormalities. Journal of Computer Assisted Tomography 2: 600.

8. Zajicek J (1974) Aspiration Biopsy Cytology: Cytology of supradiaphragmatic organs. Science, Basle.

9. Kaminsky DB (1981) Aspiration biopsy for the community hospital. Masson Publishing, New York, USA.

10. Cowell RL, Meinkoth JH (2002) Sample collection and preparation in cytology: increasing diagnostic yield. Vet. Clin. North Am Small Anim. Pract. 32: 11871235.

11. Christopher MM, Hotz CS, Shelly SM (2008) Use of cytology as a diagnostic method in veterinary practice and assessment of communication between veterinary practitioners and veterinary clinical pathologists. J Am Vet Med Assoc 232: 747-754.

12. Root KM (2007) The value of canine semen evaluation for practitioners. Vet Theriogenology 68: 329-337.

13. Allison RW, Velguth KE (2010) Appearance of granulated cells in blood films stained by automated aqueous versus methanolic Romanowsky methods. Vet Clin Pathol 39: 99-104.

14. Christopher MM, Hotz CS (2004) Cytological diagnosis: expression of probability by clinical pathologists. Vet Clin Path 33: 84-95.

15. Leopold GK (1989) Diagnostic Cytology and its Histologic Bases. (3 ${ }^{\text {rd }}$ Edn.), Philadelphia, J.B Lippincott.

16. Joan $H$ (2013) Using cytology to increase small animal practice revenue. Vet Clin Small Anim 43: 1387-1390.

17. Rakich PM, Latimer KS (2003) Cytology In: Duncan \& Prasse's veterinary laboratory medicine: clinical pathology. ( $4^{\text {th }}$ Edn.) Blackwell Publishing, USA Pp: 304-306.

18. Rebar AH (1979) Hand book of veterinary cytology. Ralston Purina \& Co. Ltd.

19. Goldschmidt MH, Hendrik MJ (2002) Tumors of the skin and soft tissues. In: Tumors in Domestic Animals. (4 $4^{\text {th }}$ Edn.)

20. Meinkoth JH, Cowell RL, Tyler RD, Morton RJ (2008) Sample collection and preparation. In: Diagnostic cytology and hematology of the dog and cat. ( $3^{\text {rd }}$ Edn.) Mosby Elsevier. pp: 1-18.

21. John D (2014) Manual of Diagnostic Cytology of the Dog and Cat. Axiom Vet John Wiley \& Sons pp: 288

22. Tseng SH, Chen YT, Huang FC (1999) Seborrheic keratosis of the conjunctiva simulating a malignant melanoma: An immunocytochemical study with impression cytology. Vet Ophthalmology 106: 1516-1520

23. Sharkey LC, Dial SM, Matz ME (2007) Maximizing the diagnostic value of cytology in small animal practice. Vet Clin Small Anim Prac 37: 351-372.

24. Pereira AV, Pereira SA, Gremial ID (2012) Comparison of acetate tape impression with squeezing versus skin scraping for the diagnosis of canine demodecosis. Aust Vet J 90: 448-450.

25. Cowell RL, Tyler RD, Meinkoth JH, DeNicola DB (1999) Diagnostic Cytology and Haematology of the Dog and Cat. Third Edition. Mosby, St. Louis (MO) USA. 
Citation: Ayele L, Mohammed C, Yimer L (2017) Review on Diagnostic Cytology: Techniques and Applications in Veterinary Medicine. J Vet Sci Technol 8: 408. doi: 10.4172/2157-7579.1000408

26. Meyer DJ, Connolly SL, Heng HG, Raskin RE, Burkhard MJ, et al. (2015) The acquisition and management of cytology specimens. Atlas of Canine and Feline Cytology. Philadelphia, PA USA: Saunders 1.

27. Villiers E, Dunn J (1998) Collection and preparation of smears for cytological examination. In Practice 20: 370-377.

28. Tseng, Waddell (2000) Approach to the patient in respiratory distress. Clinica Techniques in Small Animal Practice. 15: 53-62.

29. King F, Mousa A (2012) Fine needle aspiration immediately followed by core Needle Biopsy in the Same Setting: Modifying Our Approach. Acta Cytologica 60: $1-13$

30. De Robertis EDP, Nowinski W, Saez FA (1965) Cell Biology of General Cytology, (4 ${ }^{\text {th }}$ Edn.). WB Saunders Company, London.

31. Leveille R, Partington BP, Biller DS, Miyabayashi T (1993) Complications afte ultrasound-guided biopsy of abdominal structures in dogs and cats: 246 cases (1984-1991). J Am Vet Med Assoc 203: 413-415

32. Henson KL, Alleman RA, Leslie EF, Lauren JR, William LC (1998) Diagnosis of Disseminated Adenocarcinoma by Bone Marrow Aspiration in a Dog with Leukoerythroblastosis and Fever of Unknown Origin. Vet Clin Pathol 27: 80-84.

33. Cowell RL, Tyler RD, Meinkoth JH, Denicola DB (2008) Diagnostic cytology and hematology of the dog and cat. ( $3^{\text {rd }}$ edn). Elsevier, pp: 1-108.

34. Yager JA, Wilcock BP (1994) Color atlas and text of surgical pathology of the dog and cat. Volume 1: Dermatopathology and skin tumors. Wolfe Publishing Ltd.
35. Tyler RD, Cowell RL, Baldwin CJ (1999) Introduction in Diagnostic cytology and haematology of the dog and cat. ( $3^{\text {rd }}$ Edn.), St. Louis: Mosby, USA, Pp: 1-19.

36. Raskin RE, Meyer D (2001) General categories of cytologic interpretation. Atlas of Canine and Feline Cytology. Saunders, Philadelphia, PA, USA, Pp: 19-33.

37. Bloom F, Paff GH, Noback CR (1951) The Transmissible Venereal Tumor of the Dog: Studies Indicating That the Tumor Cells Are Mature End Cells of Reticulo-Endothelial Origin. Am J Pathol 27: 119-139.

38. Das U, Das AK (2000) Review of canine transmissible venereal sarcoma. Ve Res Comm 24: 545-556.

39. Raskin RE, Meyer DJ (2010) Canine and feline cytology: A color atlas and interpretation guide. $2^{\text {nd }}$ edn, Saunders-Elsevier

40. Igor U, Irena C, Ksenija I, Elena A, Goran N, et al. (2012) Cytological diagnostic of canine transmissible venereal tumor. Mac vet rev 35: 91-96.

41. Baker R, Lumsden J (2000) Color atlas of cytology of the dog and cat. pp: 179-183.

42. Richard M (1996) The Art and Science of Cytopathology: Exfoliative Cytology. Amer Soc Clin Pathol 1: ASCP Press.

43. Embert HC (1986) Veterinary clinical pathology. (4 ${ }^{\text {th }}$ Edn.), Saunders Company, Philadelphia, USA, pp: 252-253.

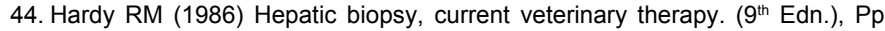
813-817. 